\title{
Erratum zu: Fließgewässer- und Auenentwicklung
}

Erratum zu:

Fließgewässer- und Auenentwicklung

Heinz Patt (Hrsg.)

ISBN 978-3-662-48448-7, DOI 10.1007/978-3-662-48449-4

2. Auflage

\section{Anmerkung}

Die Original-Version der Buch-Titelseite III wurde korrigiert.

Die Nummerierung der Abschnitte auf Seite III ist falsch. Die Abschnitte 7.4, 7.5, 7.6 und

7.7 sind mit der falschen Abschnittsnummer benannt.

Die aktualisierte Originalversion des Buchfrontmatters kann hier abgerufen werden:

DOI 10.1007/978-3-662-48449-4

(C) Springer-Verlag Berlin Heidelberg 2016

H. Patt (Hrsg.), Fließgewässer- und Auenentwicklung, DOI 10.1007/978-3-662-48449-4_8 E1 